\title{
Identification of biomarkers of chronic kidney disease among kidney-derived proteins
}

\author{
Kazuma Higashisaka ${ }^{1 *+} \odot$, Sonoko Takeya ${ }^{1 \dagger}$, Haruhiko Kamada ${ }^{2,3,4}$, Masanori Obana ${ }^{5}$, Makiko Maeda ${ }^{6}$, \\ Mai Kabayama', Koichi Yamamoto ${ }^{8}$, Nanan Ishida', Ryo Isaka' ', Hirofumi Tsujino', Kazuya Nagano', \\ Noriyuki Tomiyama ${ }^{9}$, Hiromi Rakugi ${ }^{8}$, Yasushi Fujio ${ }^{5,6}$, Kei Kamide ${ }^{7}$ and Yasuo Tsutsumi ${ }^{1,4^{*}}$
}

\begin{abstract}
Background: Chronic kidney disease (CKD) has few objective symptoms, and it is difficult to make an early diagnosis by using existing methods. Therefore, new biomarkers enabling diagnosis of renal dysfunction at an early stage need to be developed. Here, we searched for new biomarkers of CKD by focusing on kidney-derived proteins that could sensitively reflect that organ's disease state.

Methods: To identify candidate marker proteins, we performed a proteomics analysis on renal influx and efflux blood collected from the same individual.

Results: Proteomics analysis revealed 662 proteins in influx blood and 809 in efflux. From these identified proteins, we selected complement C1q as a candidate; the plasma C1q level was significantly elevated in the renal efflux of donors. Moreover, the plasma concentration of $\mathrm{Clq}$ in a mouse model of diabetic nephropathy was significantly increased, in association with increases in blood glucose concentration and urinary protein content. Importantly, we demonstrated that the tendency of C1q to increase in the plasma of CKD patients was correlated with a decrease in their estimated glomerular filtration rate.
\end{abstract}

Conclusion: Overall, our results indicate that our approach of focusing on kidney-derived proteins is useful for identifying new CKD biomarkers and that C1q has potential as a biomarker of renal function.

Keywords: Biomarker, Chronic kidney disease, Kidney-derived proteins

\section{Background}

Chronic kidney disease (CKD) is recognized as a leading public health problem worldwide, with a global estimated prevalence of $13.4 \%$ [1,2]. The loss of kidney function in CKD is progressive and irreversible [3]. Renal replacement therapies, including dialysis and kidney transplantation, are necessary for patients who progress

\footnotetext{
*Correspondence: higashisaka@phs.osaka-u.ac.jp; ytsutsumi@phs.osaka-u. ac.jp

†Kazuma Higashisaka and Sonoko Takeya are contributed equally to this work

${ }^{1}$ Laboratory of Toxicology and Safety Science, Graduate School of Pharmaceutical Sciences, Osaka University, 1-6, Yamadaoka, Suita, Osaka 565-0871, Japan

Full list of author information is available at the end of the article
}

into end-stage renal disease [4]. Because the therapeutic goal of CKD is to avoid the need for renal replacement therapy, early diagnosis of renal dysfunction and prompt elimination of the causes of dysfunction are crucial.

However, the number of CKD patients is steadily increasing year by year, and it will continue to increase [5]. This is because CKD has few symptoms, and early diagnosis is difficult with existing methods [6]. In general, renal function is evaluated by using the glomerular filtration rate, which is the amount of plasma filtered from all glomeruli of the kidney per unit time. Alternatively, physical changes in urinary levels of protein and albumin, which are test items in urinalysis, are detected daily; there are therefore many false positives, and it is difficult 
to specifically diagnose CKD. In addition, when the blood creatinine level exceeds the reference hematology value, renal function has already decreased to about $40 \%$, and it is difficult to detect the decrease in renal function at the initial stage [7]. Early identification of CKD is an important unmet medical need, not only for predicting and preventing CKD progression but also for improving patient survival and decreasing associated morbidities.

For the purpose of diagnosis of CKD, many attempts have been made to search for biomarkers by comparing variable expression levels of proteins in serum or urine between healthy subjects and patients $[8,9]$. However, it is difficult to narrow down the protein or proteins specific to the disease because it cannot be determined whether protein level variations are caused by renal dysfunction or simply by individual differences such as genetic factors and environmental background. From this viewpoint, we focused on kidney-derived proteins, which are considered to be able to sensitively reflect the state of the kidneys [10], to search for CKD biomarkers that accurately reflect renal function. In addition, we thought that it would be possible to eliminate interindividual differences, which have been a problem in proteome analysis, by comparing renal influx and efflux blood samples collected from the same individual to identify kidneyderived proteins.

Here, we attempted to identify CKD biomarkers by focusing on kidney-derived proteins and validating the expression changes of the identified proteins in an animal model with renal dysfunction.

\section{Methods}

\section{Collection of renal influx and efflux blood samples}

Blood samples were collected at the time of adrenal vein sampling, which is used to definitively diagnose primary aldosteronism. From each of seven participants, renal efflux blood was collected from the left renal vein, and renal influx blood was collected from the femoral artery, which we assumed had the same composition as the blood entering the kidney. Each sample was collected by using a blood collection tube containing a serum separator; the obtained serum was stored at $-80{ }^{\circ} \mathrm{C}$ until analysis.

\section{Proteomics analysis}

Each serum sample was centrifuged in $15,000 \mathrm{~g}$ for 5 min at $4{ }^{\circ} \mathrm{C}$, applied to a $0.45-\mu \mathrm{m}$ spin filter, and centrifuged in same condition again. To remove nonrenalspecific proteins present in large amounts in the serum, negative selection was performed via high-performance liquid chromatography (HPLC) by using a MARS Column Human-14 (Agilent Technologies, Santa Clara, CA, USA). To each 50- $\mu$ g sample, we then added $0.25 \mathrm{M}$ dithiothreitol followed by $0.375 \mathrm{M}$ iodoacetamide. We incubated the mixture for $20 \mathrm{~min}$ in the dark at room temperature, added $0.2 \mu \mathrm{g}$ trypsin, and incubated the mixture at $37{ }^{\circ} \mathrm{C}$ overnight. After the addition of $1 \%$ trifluoroacetic acid to each sample, digested peptides were desalted, purified, and concentrated with C18 microcolumns (Varian, Palo Alto, CA, USA). After lyophilization, the peptides were separated by HPLC with ion-exchange column. The supernatant underwent mass spectrometry (MS) by using a Q Exactive mass spectrometer (Thermo Fisher Scientific, Waltham, MA, USA). Identified peptides were accepted at a false discovery rate of $<1 \%$, and protein identification through a Mascot search of the Swiss-Prot database accounted for oxidation of methionine residues and thiomethylation of cysteine residues via iodoacetamide.

\section{Assessment of association of C1q with CKD in mice}

For the unilateral ureteral obstruction (UUO) model, C57BL/6 J male mice ( $\mathrm{n}=4-5$, age, 8 weeks) were anesthetized under isoflurane and the left ureter was accessed dorsally and ligated (or not, for sham-operated controls) [11]; blood was collected from the abdominal aorta 7 days after ligation. For streptozocin (STZ)-induced diabetic mice, $\mathrm{C} 57 \mathrm{BL} / 6 \mathrm{~J}$ male mice $(\mathrm{n}=5-6$, age, 8 weeks $)$ received STZ (50 mg/kg, Sigma-Aldrich, St. Louis, MO, USA) or citrate buffer ( $\mathrm{pH} 4.5)$ intraperitoneally once daily for 5 consecutive days; 11 weeks after the last dose of STZ, blood was collected from the abdominal femoral artery. The urinary protein level in each mouse was measured by using Micro TP-Test photometric (FujiFilm Wako Pure Chemical Corporation, Osaka, Japan) according to the manufacturer's protocol. Blood glucose concentration was measured by using a LabAssay Glucose kit (FujiFilm Wako Pure Chemical Corporation) according to manufacturer's protocol.

\section{Collection of human peripheral blood samples}

Serum from blood samples that had been collected from random patients (Table 1) was stored at $-80{ }^{\circ} \mathrm{C}$ until analysis. None of three non-CKD patients had proteinuria, and the estimated GFR exceeded $60 \mathrm{ml} / \mathrm{min}$ in all 3 of these patients. In addition, two of these three patients had diabetes mellitus.

\section{Quantitative analysis of C1q}

Serum levels of $\mathrm{C} 1 \mathrm{q}$ were measured by using commercial enzyme-linked immunosorbent assay (ELISA) kits according to the manufacturer's instructions. For measuring serum levels of $\mathrm{C} 1 \mathrm{q}$ in human, the ELISA kit was purchased from Abcam (Cambridge, United Kingdom); for mouse serum, the ELISA kit was purchased from R\&D Systems (Minneapolis, MN, USA). 
Table 1 Clinical characteristics of non-CKD patients and patients with CKD

\begin{tabular}{|c|c|c|c|c|c|c|c|c|}
\hline & \multicolumn{8}{|c|}{ Patient no. } \\
\hline & 1 & 2 & 3 & 4 & 5 & 6 & 7 & 8 \\
\hline Age & 48 & 76 & 71 & 88 & 84 & 67 & 85 & 68 \\
\hline Sex & M & M & $\mathrm{F}$ & M & M & M & $F$ & M \\
\hline Diabetes mellitus & No & Yes & Yes & Yes & Yes & Yes & Yes & No \\
\hline CKD & No & Yes & No & Yes & No & Yes & Yes & Yes \\
\hline $\mathrm{eGFR}\left(\mathrm{mL} / \mathrm{min} / 1.73 \mathrm{~m}^{2}\right)$ & 65 & 58.5 & 75.1 & 40.3 & 76.7 & 81 & 65.3 & 26.9 \\
\hline Proteinuria & No & Yes & No & No & No & Yes & Yes & Yes \\
\hline
\end{tabular}

\section{Statistical analyses}

Statistical analyses were performed by using Ekuseru-Toukei 2008 software (Social Survey Research Information, Tokyo, Japan). All data are expressed as means \pm S.E.M. and were compared by using $t$-tests; $P<0.05$ was considered significant.

\section{Results}

\section{Identification of kidney-derived proteins}

To identify kidney-derived proteins, renal influx and efflux blood samples were collected from seven human individuals and underwent proteomic analysis by LCMS/MS. Comprehensive assessment revealed 662 proteins in total in the influx blood and 809 in the efflux blood. To select candidate kidney-derived proteins from among all identified proteins, we calculated the ratio of each protein's expression level in the efflux sample to its expression in the influx sample by using the area value, which is the integrated value of the signal intensity of the identified peptide. Consequently, depending on the protein, the expression ratio varied among the seven individuals' samples, and for some proteins in some samples we could not calculate the expression ratio because the protein's area value was below the lower limit for that parameter $\left(1 \times 10^{6}\right)$. Therefore, we averaged the expression ratios from all seven individuals (Fig. 1a and Additional file 1: Table S1) and focused on proteins whose efflux:influx expression ratio was $>1.5$ in at least five donors and $>3$ in at least two donors (Table 2). The top three proteins were the three peptides that comprised (a)

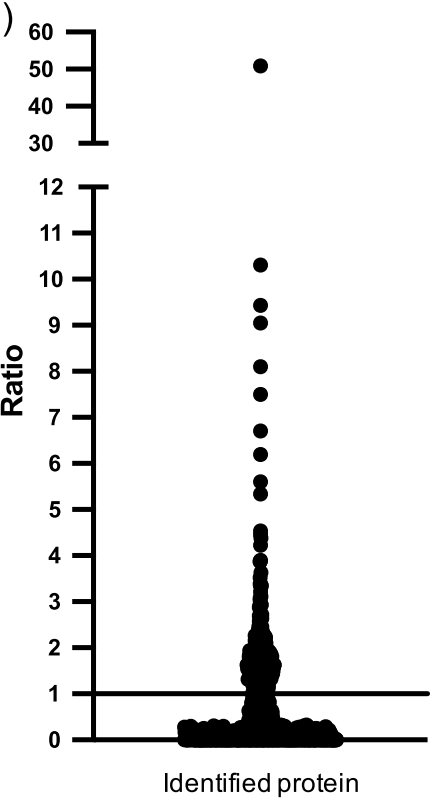

(b)

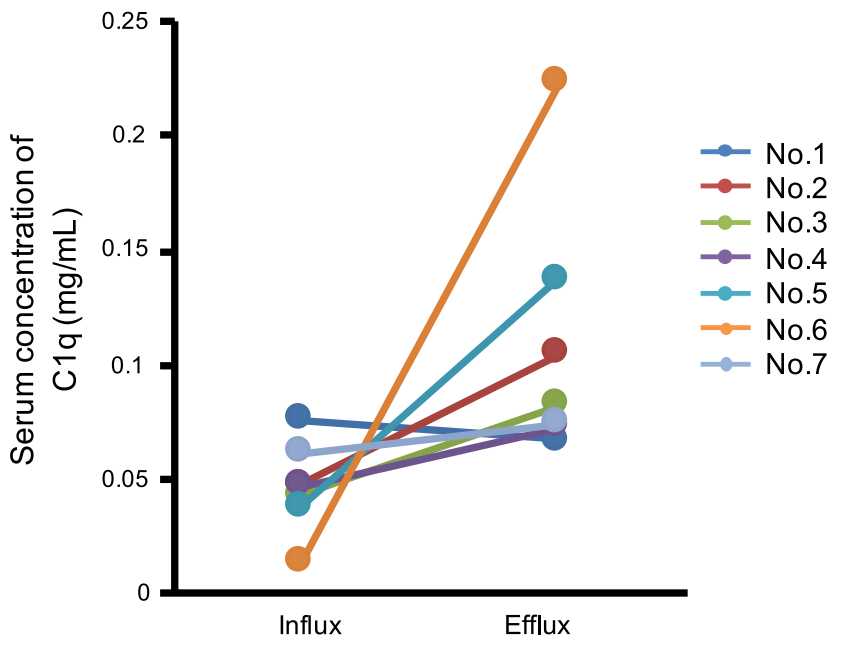

Fig. 1 Concentrations of $\mathrm{C} 1 \mathrm{q}$ in renal influx and efflux blood samples from human individuals. a Averaged ratio of each protein's expression level in the efflux sample to its expression in the influx from all seven individuals. b C1q concentrations in renal influx and efflux blood samples from each of seven individuals (nos. 1-7) were examined by enzyme-linked immunosorbent assay (ELISA) 
Table 2 Candidate kidney-derived proteins and their efflux:influx expression ratios in seven individuals

\begin{tabular}{|c|c|c|c|c|c|c|c|c|}
\hline \multirow[t]{2}{*}{ Protein } & \multicolumn{8}{|c|}{ Donor no. } \\
\hline & 1 & 2 & 3 & 4 & 5 & 6 & 7 & Average \\
\hline Complement C1q subcomponent subunit A & 3.35 & 4.48 & 4.60 & 9.16 & 3.22 & 2.56 & 38.66 & 9.43 \\
\hline Complement C1q subcomponent subunit B & 6.35 & 12.27 & 0.58 & 21.21 & 5.72 & 2.75 & 14.47 & 9.05 \\
\hline Complement C1q subcomponent subunit C & 7.78 & 10.61 & 4.28 & 17.80 & 6.12 & 2.80 & 7.32 & 8.10 \\
\hline Apolipoprotein(a) & 2.23 & 13.08 & 1.08 & 2.79 & 4.83 & 2.99 & 16.42 & 6.20 \\
\hline Protein Z-dependent protease inhibitor & 0.05 & 1.83 & 1.79 & 2.00 & 9.45 & 1.41 & 22.67 & 5.60 \\
\hline Corticosteroid-binding globulin & 2.30 & 2.27 & 2.28 & 3.38 & 4.32 & 2.14 & 15.1 & 4.54 \\
\hline Lysosome-associated membrane glycoprotein 1 & 2.46 & 4.67 & 13.46 & 1.81 & 1.99 & 4.13 & 2.62 & 4.45 \\
\hline Phosphatidylinositol-glycan-specific phospholipase D & 2.56 & 7.67 & 7.88 & 6.24 & 1.28 & 1.36 & 2.63 & 4.23 \\
\hline Plasma serine protease inhibitor & 1.91 & 6.60 & 7.36 & 5.81 & 2.14 & 3.46 & 000 & 3.90 \\
\hline Apolipoprotein C-IV & 4.69 & 8.70 & 2.15 & 4.60 & 0.77 & 1.47 & 3.02 & 3.63 \\
\hline
\end{tabular}

The efflux:influx ratio of each protein identified by LC-MS/MS was calculated for each individual

The top 10 candidate proteins, whose efflux:influx ratio exceeded 1.5 in at least five individuals and exceeded 3.0 in at least two individuals, are indicated

the subunits of complement $\mathrm{C} 1 \mathrm{q}$; we therefore selected complement $\mathrm{C} 1 \mathrm{q}$ itself as a new candidate renal secretory protein.

We then used ELISA to measure the amount of $\mathrm{C} 1 \mathrm{q}$ in the renal influx and efflux blood samples. C1q was increased in the efflux samples from all individuals except no. 1 (Fig. 1b). In addition, the mean serum C1q concentration was significantly higher in efflux blood $(0.109 \pm 0.0211 \mathrm{mg} / \mathrm{mL})$ than in influx blood $(0.0473 \pm 0.072 \mathrm{mg} / \mathrm{mL})(P=0.0172$, data not shown $)$. These results indicate that $\mathrm{C} 1 \mathrm{q}$ is an appropriate candidate kidney-derived protein.

\section{Relationship between C1q concentration and renal function in mouse models of CKD}

To assess whether C1q is a potential CKD biomarker that reflects renal function, we evaluated two mouse models of CKD as representatives of the wide variety of primary diseases that lead to CKD. We first looked at STZinduced diabetic mice [12], which demonstrate diabetic nephropathy, a leading cause of CKD $[13,14]$. The serum C1q concentration was significantly greater in the STZ group than in the vehicle-only control group (Fig. 2a). In addition, blood glucose concentration (Fig. 2b) and urinary protein content (Fig. 2c) both were positively correlated with serum $\mathrm{C} 1 \mathrm{q}$ concentration $(r=0.679$ and $r=0.511$, respectively).

As the second model, we used UUO mice, in which renal fibrosis was induced by ligating the left ureter. Renal fibrosis is a common feature of CKD regardless of the causative disease [15], and the degree of fibrosis is correlated with disease progression [16, 17]. However, the serum concentration of $\mathrm{C} 1 \mathrm{q}$ did not differ significantly between UUO mice and the sham-operated group (Fig. 2d). These results suggest that $\mathrm{C} 1 \mathrm{q}$ is a biomarker that at least reflects the renal dysfunction associated with diabetes.

\section{Association of $\mathrm{C} 1 \mathrm{q}$ concentration with renal function in human patients}

To evaluate whether $\mathrm{C} 1 \mathrm{q}$ reflects renal dysfunction in humans, we measured the C1q concentration in peripheral blood serum from three non-CKD patients and five patients with CKD. When we used these samples without adjustment for donor age, serum $\mathrm{C} 1 \mathrm{q}$ concentration tended to show a positive correlation $(r=-0.713)$ with estimated glomerular filtration rate (eGFR) (Fig. 3a). However, the blood concentration of $\mathrm{C} 1 \mathrm{q}$ reportedly increases with age, and eGFR decreases with age [18, 19]. We therefore assessed the correlation between a patients' age and C1q concentration (Fig. 3b) or eGFR (Fig. 3c); these analyses yielded correlation coefficients of 0.154 and -0.100 , respectively, indicating no correlation between these parameters. Overall, these results suggest that the serum concentration of $\mathrm{Clq}$ in humans reflects their renal function and that $\mathrm{C} 1 \mathrm{q}$ has potential as a biomarker of CKD.

\section{Discussion}

This research indicates that our approach of focusing on kidney-derived proteins, which are considered to sensitively reflect the state of the kidneys, is useful for identifying new CKD biomarkers; through this approach, we identified $\mathrm{C} 1 \mathrm{q}$ is as a candidate kidneyderived protein. Although several reports have discussed the relationship between $\mathrm{C1q}$ and renal status, few previously discussed $\mathrm{C} 1 \mathrm{q}$ in terms of it being a kidney-derived protein. In addition, we demonstrated that the serum $\mathrm{C} 1 \mathrm{q}$ concentration tended to show a positive correlation with the estimated GFR of human 

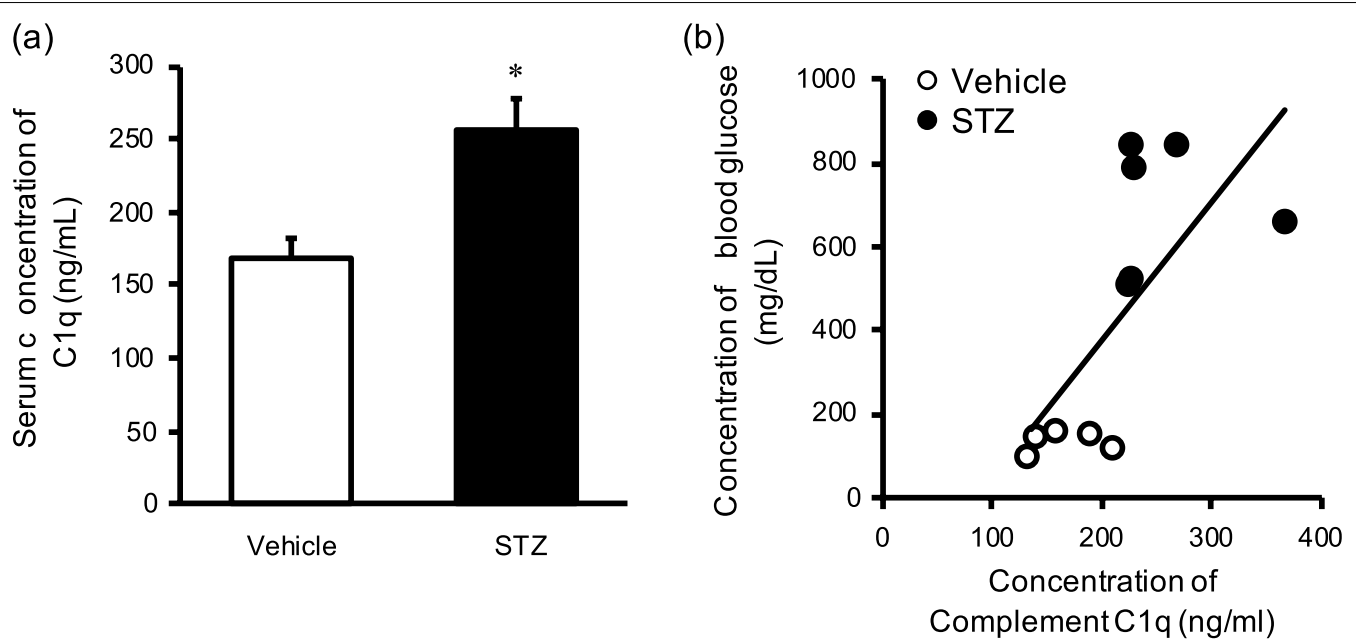

(c)

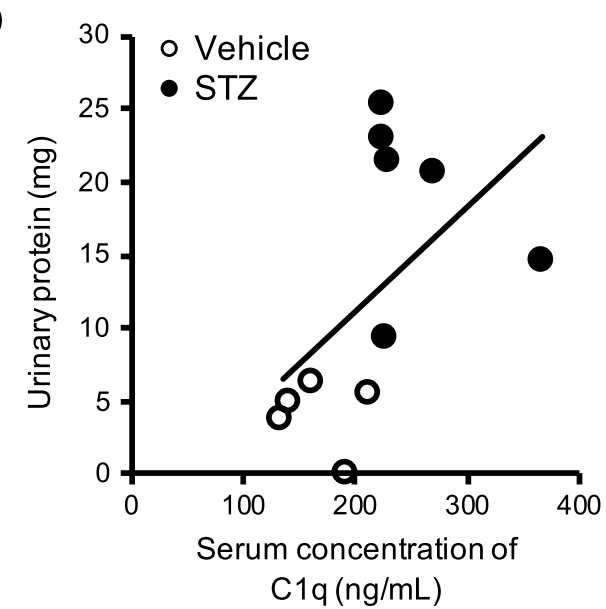

(d)

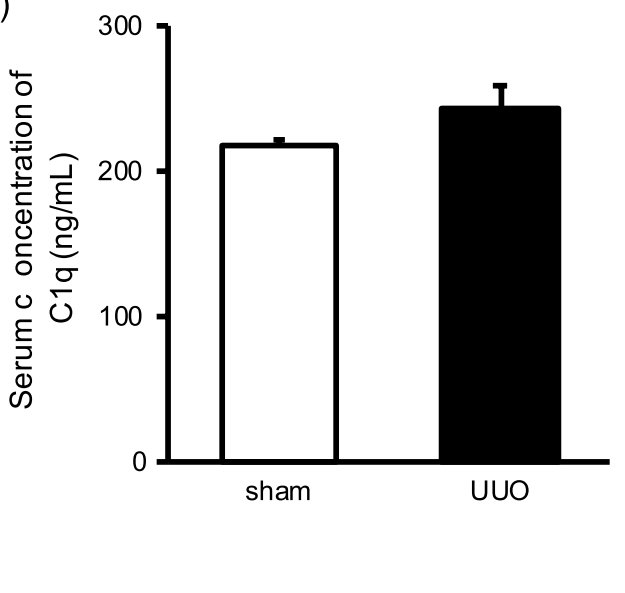

Fig. 2 Usefulness of C1q as a biomarker of chronic kidney disease (CKD) in mice. a Serum concentrations of C1q in streptozocin (STZ)-induced diabetic and vehicle control mice were examined by ELISA; the mean value was significantly higher in the diabetic mice. In each mouse, the serum C1q concentration was correlated with the $\mathbf{b}$ blood glucose level and $\mathbf{c}$ amount of urinary protein. $\mathbf{d}$ Serum concentrations of C1q in unilateral ureteral obstruction (UUO) and sham-operated control mice were examined by ELISA; the mean value did not differ between groups. Data are expressed as means \pm S.E.M. $(n=4-6) .{ }^{*}, P<0.05$ (t-test) compared with value for controls

patients, suggesting that, in humans, C1q has potential to reflect their renal function. Therefore, we hope that the approach that we developed in the current study will make it easier to identify other kidney-derived proteins with potential as CKD biomarkers.

The efflux:influx expression ratio differed between the proteome analysis and the quantitative analysis by ELISA. We consider that the differences between the quantitativeness and identification target of each method underlie the apparently inconsistent results. In the quantitative analysis by ELISA, the expression level of a protein is analyzed by using two types of antibodies that recognize different epitopes. Whereas an antibody-based identification method focuses on a specific region of a three-dimensional protein, a mass spectrometer focuses on a specific linear peptide sequence. This methodologic difference leads to a difference in identification sensitivity and likely is responsible for the different efflux:influx expression ratios that we obtained through proteomics analysis compared with ELISA.

To develop C1q as a biomarker of the chronic inflammatory pathology of CKD, the constitutive role of $\mathrm{C} 1 \mathrm{q}$ in the kidney and the mechanism of its increased expression in renal dysfunction must be understood. $\mathrm{C} 1 \mathrm{q}$ is the first component of the classical pathway of the complement system [19] and is primarily produced by activated dendritic cells [20]. Therefore, regarding the renal secretory mechanism of $\mathrm{C} 1 \mathrm{q}$, the increased 

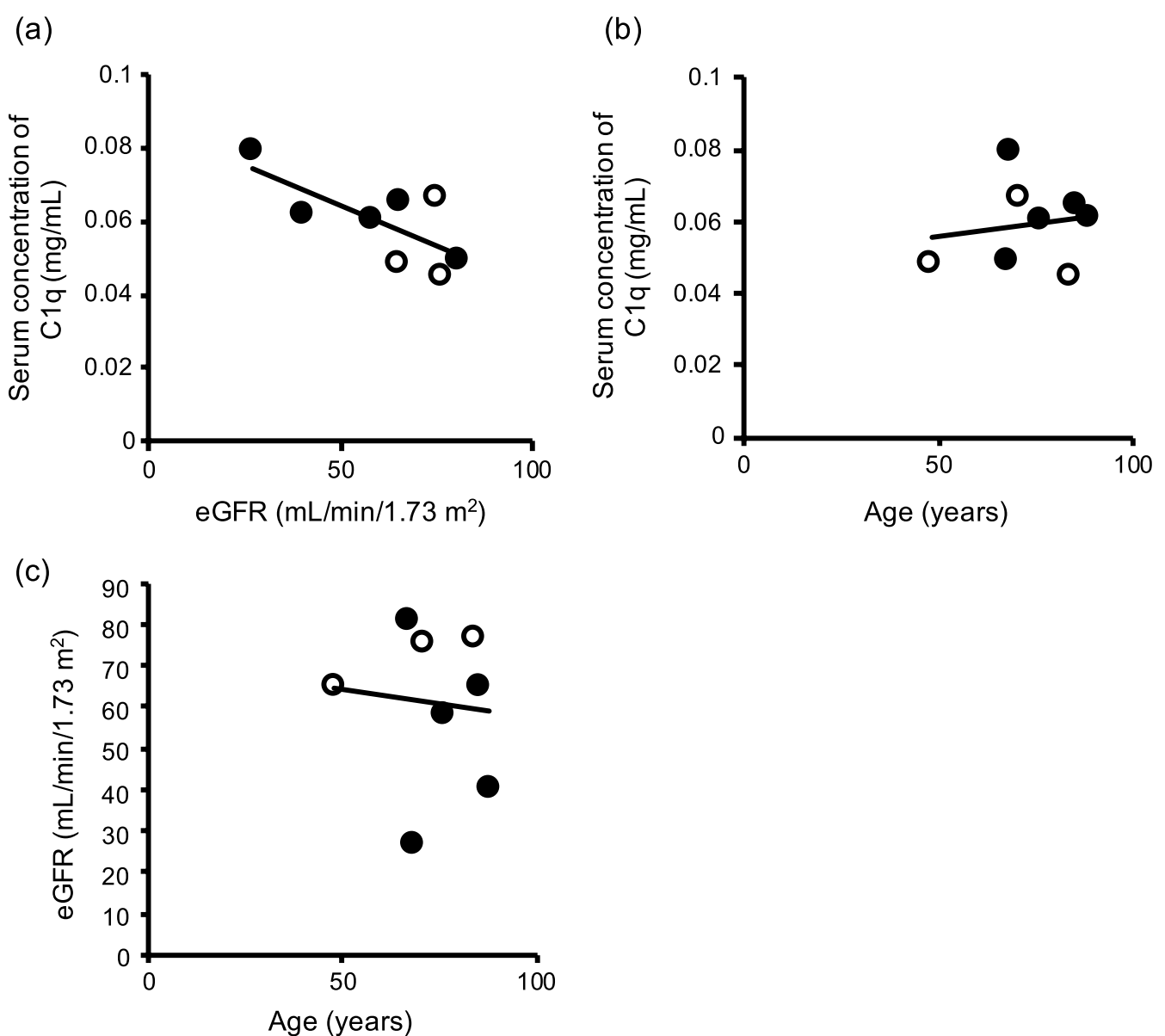

Fig. 3 Association of C1q concentration with renal function in human patients with CKD. a Peripheral serum concentrations of C1q in non-CKD patients (white circles) and in patients with CKD (black circles) were examined by ELISA. The correlation between the serum C1q and estimated glomerular filtration rate (eGFR) is shown. Peripheral serum C1 q concentration was not correlated with a patient's b age or c eGFR

C1q concentration associated with CKD may reflect the infiltration of macrophages into the kidney.

In addition, the sensitivity and specificity of a candidate biomarker for a target disease are important. From the viewpoint of sensitivity, blood levels of C1q can be quantified, demonstrating its suitability for minimally invasive blood tests. However, from the viewpoint of specificity, blood levels of $\mathrm{C} 1 \mathrm{q}$ are increased in rheumatoid arthritis [21] and sarcopenia [22]. Furthermore, considering that CKD is a consequence of numerous and diverse primary diseases with complicated underlying pathology, it will be difficult to diagnose CKD solely on the basis of blood levels of C1q. Therefore, accurate diagnosis of CKD will require the use of multiple biomarkers, including $\mathrm{C} 1 \mathrm{q}$ $[23,24]$. The approach we developed in the current study likely will be useful for identifying other kidney-derived proteins with potential as CKD biomarkers.

Regarding the relationship between $\mathrm{C} 1 \mathrm{q}$ and the kidney, the clinical condition of C1q nephropathy is associated with profound protein loss through the urine and the deposition of C1q in the kidney $[25,26]$. The mechanisms underlying the onset of C1q nephropathy and renal deposition of C1q have not yet been clarified, but the C1q deposits reportedly activate the renal immune system, leading to an inflammatory immune response and inflammation-induced renal damage [27, 28]. Given that the induction of an inflammatory response is involved in the progression of CKD and that, compared with healthy subjects, CKD patients have increased blood cytokine levels [29, 30], perhaps C1q acts as an exacerbating factor in the inflammation-associated decline of renal function during CKD. We plan to use various mouse models of CKD to disclose the role of C1q in the kidney.

Moreover, CKD-like arteriosclerosis, decreased skeletal muscle mass, and cognitive dysfunction-can be regarded as a marker of aging at the individual level [31]. In this regard, the klotho/Wnt/ $\beta$-catenin pathway is known to be involved in the renal fibrosis of aged kidneys 
and of CKD, because klotho expression is reduced in aged or impaired kidneys [32] and because the activation of Wnt signaling is responsible for the aging phenotype in klotho mice [33]. Given that C1q is involved in the activation of Wnt signaling activation in vivo [19], C1qinduced activation of Wnt signaling conceivably may be involved in aging and aging-related organ or tissue dysfunction. In addition, the majority of patients with CKD die from cardiovascular disease (CVD) before progressing to end-stage renal disease [34, 35]. CKD-associated CVD typically leads to clinical outcomes such as sudden cardiac death and hospitalization for heart failure [36]. Considerable effort has been devoted to investigating the etiology and pathogenesis involved in the progression of CKD-associated CVD, including the retention of uremic toxins and inflammation [37], but the high-risk factors and their underlying mechanisms are still far from being elucidated. However, given that $\mathrm{C} 1 \mathrm{q}$ may promote agingassociated arteriosclerosis [38], the increased levels of C1q in patients with CKD might contribute to the etiology of CKD and its pathogenesis, including the progression of CVD. Together, these previous findings and our current results indicate the potential usefulness of $\mathrm{C} 1 \mathrm{q}$ as a biomarker for the chronic inflammatory pathology of CKD.

\section{Conclusion}

Our results indicate that our approach of focusing on kidney-derived proteins is useful for identifying new CKD biomarkers and that C1q has potential as a biomarker of renal function.

\section{Abbreviations \\ CKD: Chronic kidney disease; CVD: Cardiovascular disease; eGFR: Esti- mated glomerular filtration rate; STZ: Streptozocin; UUO: Unilateral ureteral obstruction.}

\section{Supplementary Information}

The online version contains supplementary material available at https://doi. org/10.1186/s12014-021-09340-y.

Additional file 1: Table S1. Identified kidney-derived proteins and their efflux:influx expression ratios in seven individuals.

\section{Acknowledgements}

Not applicable.

\section{Authors' contributions}

$\mathrm{KH}, \mathrm{YF}, \mathrm{KK}$, and $\mathrm{YT}$ designed the study; ST, HK, MO, NI, and RI performed experiments and analyzed data; KH and ST wrote the manuscript; MM, MK, KY, HT, KN and NT provided technical support and conceptual advice; H.R. and Y.T. supervised all projects. All authors have read and approved the final manuscript.

\section{Funding}

This study was supported by Grants-in-Aid for Scientific Research from the Japan Society for the Promotion of Science (No. 26242055 to Y.T.).
Availability of data and materials

All data generated or analyzed during this study are included in this published article.

\section{Declarations}

\section{Ethics approval and consent to participate}

The samples were collected from volunteers and patients who provided written informed consent to a clinical study at the outpatient clinic of Osaka University Hospital. The samples were used with the approval of the Ethics Review Committee of Osaka University Hospital (Protocol No. 14060-2). From the perspective of personal information protection, the samples were linkable and anonymized. The correspondence table was stored at the Division of Health Sciences, Osaka University Graduate School of Medicine, and individual patients could not be identified at Osaka University Graduate School of Pharmaceutical Sciences.

\section{Consent for publication}

Not applicable.

\section{Competing interests}

The authors declare that they have no competing interests.

\section{Author details}

${ }^{1}$ Laboratory of Toxicology and Safety Science, Graduate School of Pharmaceutical Sciences, Osaka University, 1-6, Yamadaoka, Suita, Osaka 565-0871, Japan. ${ }^{2}$ Laboratory of Biopharmaceutical Research, National Institutes of Biomedical Innovation, Health and Nutrition, Ibaraki, Osaka, Japan. ${ }^{3}$ Center for Drug Design Research, National Institutes of Biomedical Innovation, Health and Nutrition, Ibaraki, Osaka, Japan. ${ }^{4}$ Global Center for Medical Engineering and Informatics, Osaka University, Suita, Osaka, Japan. ${ }^{5}$ Laboratory of Clinical Science and Biomedicine, Graduate School of Pharmaceutical Sciences, Osaka University, Suita, Osaka, Japan. ${ }^{6}$ Advanced Research of Medical and Pharmaceutical Sciences, Graduate School of Pharmaceutical Sciences, Osaka University, Suita, Osaka, Japan. ' Department of Health Promotion Sciences, Division of Health Sciences, Osaka University Graduate School of Medicine, Suita, Osaka, Japan. ${ }^{8}$ Department of Geriatric and General Medicine, Osaka University Graduate School of Medicine, Suita, Osaka, Japan. ${ }^{9}$ Department of Radiology, Osaka University Graduate School of Medicine, Suita, Osaka, Japan.

Received: 2 August 2021 Accepted: 30 December 2021

Published online: 11 January 2022

\section{References}

1. Hill NR, Fatoba ST, Oke JL, Hirst JA, O'Callaghan CA, Lasserson DS, Hobbs FD. Global prevalence of chronic kidney disease - a systematic review and meta-analysis. PLOS ONE. 2016;11(7): e0158765.

2. Shabaka A, Cases-Corona C, Fernandez-Juarez G. Therapeutic insights in chronic kidney disease progression. Front Med (Lausanne). 2021;8: 645187.

3. Cao Q, Chen XM, Huang C, Pollock CA. MicroRNA as novel biomarkers and therapeutic targets in diabetic kidney disease: an update. FASEB Bioadv. 2019;1(6):375-88.

4. Neovius M, Jacobson SH, Eriksson JK, Elinder CG, Hylander B. Mortality in chronic kidney disease and renal replacement therapy: a populationbased cohort study. BMJ Open. 2014;4(2): e004251.

5. Sladoje-Martinovic B, Mikolasevic I, Bubic I, Racki S, Orlic L. Survival of chronic hemodialysis patients over 80 years of age. Clin Interv Aging. 2014;9:689-96

6. Lousa I, Reis F, Beirao I, Alves R, Belo L, Santos-Silva A. New potential biomarkers for chronic kidney disease management-a review of the literature. Int J Mol Sci. 2020. https://doi.org/10.3390/ijms22010043.

7. Zhang WR, Parikh CR. Biomarkers of acute and chronic kidney disease. Annu Rev Physiol. 2019;81:309-33.

8. Bidin MZ, Shah AM, Stanslas J, Seong CLT. Blood and urine biomarkers in chronic kidney disease: an update. Clin Chim Acta. 2019;495:239-50. 
9. Taherkhani A, Farrokhi Yekta R, Mohseni M, Saidijam M, Arefi Oskouie A. Chronic kidney disease: a review of proteomic and metabolomic approaches to membranous glomerulonephritis, focal segmental glomerulosclerosis, and IgA nephropathy biomarkers. Proteome Sci. 2019;17:7.

10. Palviainen M, Raekallio M, Rajamaki MM, Linden J, Vainio O. Kidneyderived proteins in urine as biomarkers of induced acute kidney injury in sheep. Vet J. 2012;193(1):287-9.

11. Yamamoto A, Morioki H, Nakae T, Miyake Y, Harada T, Noda S, Mitsuoka S, Matsumoto K, Tomimatsu M, Kanemoto S, et al. Transcription factor old astrocyte specifically induced substance is a novel regulator of kidney fibrosis. FASEB J. 2021;35(2): e21158.

12. Deeds MC, Anderson JM, Armstrong AS, Gastineau DA, Hiddinga HJ, Jahangir A, Eberhardt NL, Kudva YC. Single dose streptozotocin-induced diabetes: considerations for study design in islet transplantation models. Lab Anim. 2011;45(3):131-40.

13. Lim A. Diabetic nephropathy — complications and treatment. Int J Nephrol Renovasc Dis. 2014;7:361-81.

14. Lin YC, Chang YH, Yang SY, Wu KD, Chu TS. Update of pathophysiology and management of diabetic kidney disease. J Formos Med Assoc. 2018;117(8):662-75

15. Vazquez-Mendez E, Gutierrez-Mercado Y, Mendieta-Condado E, GalvezGastelum FJ, Esquivel-Solis H, Sanchez-Toscano Y, Morales-Martinez C, Canales-Aguirre AA, Marquez-Aguirre AL. Recombinant erythropoietin provides protection against renal fibrosis in adenine-induced chronic kidney disease. Mediators Inflamm. 2020;2020:8937657.

16. Tang PM, Nikolic-Paterson DJ, Lan HY. Macrophages: versatile players in renal inflammation and fibrosis. Nat Rev Nephrol. 2019;15(3):144-58.

17. Tang PC, Chan AS, Zhang CB, Garcia Cordoba CA, Zhang YY, To KF, Leung KT, Lan HY, Tang PM. TGF-beta1 signaling: immune dynamics of chronic kidney diseases. Front Med (Lausanne). 2021;8: 628519.

18. Mujtaba SH, AshrafT, Mahmood SN, Anjum Q. Assessment of renal insufficiency in patients with normal serum creatinine levels undergoing angiography. J Pak Med Assoc. 2010;60(11):915-7.

19. Naito AT, Sumida T, Nomura S, Liu ML, Higo T, Nakagawa A, Okada K, Sakai T, Hashimoto A, Hara Y, et al. Complement C1 q activates canonical Wnt signaling and promotes aging-related phenotypes. Cell. 2012;149(6):1298-313

20. Lu JH, Teh BK, Wang L, Wang YN, Tan YS, Lai MC, Reid KB. The classical and regulatory functions of $\mathrm{C} 1 \mathrm{q}$ in immunity and autoimmunity. Cell $\mathrm{Mol}$ Immunol. 2008;5(1):9-21.

21. Olsen NJ, Ho E, Barats L. Clinical correlations with serum C1q levels in patients with rheumatoid arthritis. Arthritis Rheum. 1991;34(2):187-91.

22. Watanabe S, Sato K, Hasegawa N, Kurihara T, Matsutani K, Sanada K, Hamaoka T, Fujita S, lemitsu M. Serum C1q as a novel biomarker of sarcopenia in older adults. FASEB J. 2015;29(3):1003-10.

23. Yanagawa H, Suzuki H, Suzuki Y, Kiryluk K, Gharavi AG, Matsuoka K, Makita Y, Julian BA, Novak J, Tomino Y. A panel of serum biomarkers differentiates IgA nephropathy from other renal diseases. PLoS ONE. 2014;9(5): e98081.

24. Watson D, Yang JYC, Sarwal RD, Sigdel TK, Liberto JM, Damm I, Louie V, Sigdel S, Livingstone $\mathrm{D}$, Soh $\mathrm{K}$, et al. A novel multi-biomarker assay for non-invasive quantitative monitoring of kidney injury. J Clin Med. 2019. https://doi.org/10.3390/jcm8040499.

25. Wenderfer SE, Swinford RD, Braun MC. C1q nephropathy in the pediatric population: pathology and pathogenesis. Pediatr Nephrol. 2010;25(8):1385-96

26. Portilla D, Xavier S. Role of intracellular complement activation in kidney fibrosis. Br J Pharmacol. 2021. https://doi.org/10.1111/bph.15408.

27. Mii A, Shimizu A, Masuda Y, Fujita E, Aki K, Ishizaki M, Sato S, Griesemer A, Fukuda Y. Current status and issues of C1q nephropathy. Clin Exp Nephrol. 2009;13(4):263-74.

28. Sun J, Guo S, Niu F, Liu D, Zhuang Y. Complement 1q protects MRL/lpr mice against lupus nephritis via inhibiting the nuclear factor-kappaB pathway. Mol Med Rep. 2020;22(6):5436-43.

29. Tucker PS, Scanlan AT, Dalbo VJ. Chronic kidney disease influences multiple systems: describing the relationship between oxidative stress, inflammation, kidney damage, and concomitant disease. Oxid Med Cell Longev. 2015;2015: 806358.

30. Amdur RL, Feldman HI, Gupta J, Yang W, Kanetsky P, Shlipak M, Rahman M, Lash JP, Townsend RR, Ojo A, et al. Inflammation and progression of CKD: The CRIC Study. Clin J Am Soc Nephrol. 2016;11(9):1546-56.
31. Shanahan CM. Mechanisms of vascular calcification in CKD-evidence for premature ageing? Nat Rev Nephrol. 2013;9(11):661-70.

32. Satoh M, Nagasu H, Morita Y, Yamaguchi TP, Kanwar YS, Kashihara N. Klotho protects against mouse renal fibrosis by inhibiting Wnt signaling. Am J Physiol Renal Physiol. 2012;303(12):F1641-1651.

33. Liu H, Fergusson MM, Castilho RM, Liu J, Cao L, Chen J, Malide D, Rovira II, Schimel D, Kuo CJ, et al. Augmented Wnt signaling in a mammalian model of accelerated aging. Science. 2007;317(5839):803-6.

34. Vallianou NG, Mitesh S, Gkogkou A, Geladari E. Chronic kidney disease and cardiovascular disease: is there any relationship? Curr Cardiol Rev. 2019;15(1):55-63.

35. Sadeghi-Alavijeh O, Tadayyon M, Caplin B. Chronic kidney disease-associated cardiovascular disease: scope and limitations of animal models. Cardiovasc Endocrinol. 2017;6(4):120-7.

36. Collins AJ, Foley R, Herzog C, Chavers B, Gilbertson D, Ishani A, Kasiske B, Liu J, Mau LW, McBean M, et al. Excerpts from the United States Renal Data System 2007 annual data report. Am J Kidney Dis. 2008;51(1 Suppl 1):S1-320.

37. Sarnak MJ, Amann K, Bangalore S, Cavalcante JL, Charytan DM, Craig JC, Gill JS, Hlatky MA, Jardine AG, Landmesser U, et al. Chronic kidney disease and coronary artery disease: JACC State-of-the-Art Review. J Am Coll Cardiol. 2019;74(14):1823-38.

38. Hasegawa N, Fujie S, Horii N, Uchida M, Toyama Y, Inoue K, Sanada K, Hamaoka T, lemitsu M. Aging-induced elevation in circulating complement C1q level is associated with arterial stiffness. Exp Gerontol. 2019;124: 110650.

\section{Publisher's Note}

Springer Nature remains neutral with regard to jurisdictional claims in published maps and institutional affiliations.

Ready to submit your research? Choose BMC and benefit from:

- fast, convenient online submission

- thorough peer review by experienced researchers in your field

- rapid publication on acceptance

- support for research data, including large and complex data types

- gold Open Access which fosters wider collaboration and increased citations

- maximum visibility for your research: over $100 \mathrm{M}$ website views per year

At BMC, research is always in progress.

Learn more biomedcentral.com/submissions 